\title{
Effect of Silicate Pretreatment on Lanthanum Conversion Coating of Hot-dip Galvanized Steel
}

\author{
Shuanghong Zhang ${ }^{1, *}$, Bo Yang ${ }^{1}$, Gang Kong ${ }^{2}$, Jintang $L u^{2}$ \\ ${ }^{1}$ Guangzhou Special Pressure Equipment Inspection and Research Institute, Keyan Road No.9, \\ Huangpu District, Guangzhou 510663, China \\ ${ }^{2}$ School of Material Science and Engineering, South China University of Technology, Wushan Road \\ No.381, Tianhe District, Guangzhou 510640, China \\ *E-mail: zshscut@163.com.
}

doi: $10.20964 / 2018.11 .04$

Received: 6 June 2018 / Accepted: 2 August 2018 / Published: 1 October 2018

\begin{abstract}
Modified lanthanum conversion coatings were obtained by immersing hot-dip galvanized (HDG) steel sheets that underwent silicate pretreatment in a lanthanum nitrate solution. The results of potentiodynamic polarization and electrochemical impedance spectroscopy (EIS) measurements revealed that silicate pretreatment improved the protective property of the lanthanum conversion coatings, and this conclusion was then corroborated by neutral salt spray (NSS) tests. The morphology and chemical compositions of coatings were examined by scanning electron microscopy (SEM), energy dispersive spectroscopy (EDS), scanning tunnelling microscopy (STM) and Auger electron spectroscopy (AES). The results showed that many silicate particles were dispersed evenly onto the surface of HDG after silicate pretreatment; as a result, the growth of the lanthanum conversion coatings tended to be homogeneous, so that more uniform and compact coatings can be obtained.
\end{abstract}

Keywords: Hot-dip galvanized steel, lanthanum conversion coating, EIS, corrosion resistance, silicate pretreatment

\section{$\underline{\text { FULL TEXT }}$}

(C) 2018 The Authors. Published by ESG (www.electrochemsci.org). This article is an open access article distributed under the terms and conditions of the Creative Commons Attribution license (http://creativecommons.org/licenses/by/4.0/). 